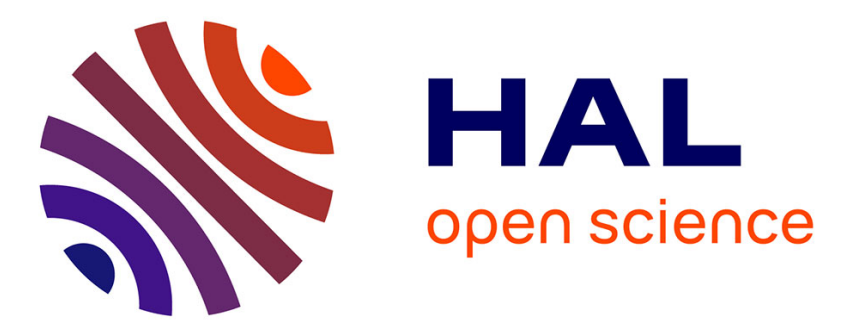

\title{
Wetting behaviors of the Ti2AlC ceramics by nickel and aluminum fillers
}

\author{
Chengjie Lu, Liangbo Sun, Qin Qi, Jie Zhang, Gilles Hug
}

\section{To cite this version:}

Chengjie Lu, Liangbo Sun, Qin Qi, Jie Zhang, Gilles Hug. Wetting behaviors of the Ti2AlC ceramics by nickel and aluminum fillers. Materials Letters, 2018, 219, pp.240-242. 10.1016/j.matlet.2018.02.077 . hal-02319668

\section{HAL Id: hal-02319668 \\ https://hal.science/hal-02319668}

Submitted on 2 Nov 2021

HAL is a multi-disciplinary open access archive for the deposit and dissemination of scientific research documents, whether they are published or not. The documents may come from teaching and research institutions in France or abroad, or from public or private research centers.
L'archive ouverte pluridisciplinaire HAL, est destinée au dépôt et à la diffusion de documents scientifiques de niveau recherche, publiés ou non, émanant des établissements d'enseignement et de recherche français ou étrangers, des laboratoires publics ou privés. 


\title{
Wetting behaviors of the $\mathrm{Ti}_{2} \mathrm{AlC}$ ceramics by nickel and aluminum fillers
}

\author{
Chengjie Lu ${ }^{1,2}$, Liangbo Sun ${ }^{1}$, Qin $\mathrm{Qi}^{1}$, Jie Zhang ${ }^{1,{ }^{*}}$, Gilles Hug ${ }^{2}$ \\ ${ }^{I}$ School of Materials Science and Engineering, Harbin Institute of Technology, Harbin 150001, China \\ ${ }^{2}$ Laboratoire d'Études des Microstructures, CNRS-ONERA, Châtillon 92322, France
}

\begin{abstract}
In the present work, the behaviors of nickel and aluminum based fillers on the $\mathrm{Ti}_{2} \mathrm{AlC}$ ceramics are studied by wetting experiments and characterization of the interface cross-section. The results show that the two kinds of fillers possess different wettability on the $\mathrm{Ti}_{2} \mathrm{AlC}$ ceramics: the contact angle of the nickel fillers decreases continuously with rising temperature and reaches less than $20^{\circ}$ finally, whereas that of the aluminum fillers remains larger than $135^{\circ}$ in the full temperature range investigated. The characterization of the interface from cross-section observations reveals the presence of an interaction layer in the $\mathrm{Ti}_{2} \mathrm{AlC}$ ceramic substrate, which promotes the wetting process.
\end{abstract}

Keywords: MAX phases; wetting; interface; reaction

\section{Introduction}

In recent years, a group of nanolaminate ternary carbide or nitride ceramics have attracted considerable attention from researchers because of their excellent combination of metal and ceramic properties $[1,2]$. They have been systematically

\footnotetext{
* Corresponding author: Tel/Fax: +86 45186414234

E-mail address: hitzhangjie@hit.edu.cn (J. Zhang).
} 
introduced by Barsoum et al. [3] with the family name 'MAX' and the general formula ' $M_{n+1} A X_{n}$ ', where $M$ is an early transition metal, $A$ is an A-group element and $X$ is either carbon or nitrogen. The $n$ parameters may vary from 1 to 3 and the different structure are often named 211,312 or 413 after their composition. The $\mathrm{Ti}_{2} \mathrm{AlC}$ ceramics, a typical member of the family with $n=1$ (known as the ' 211 ' structure), have gained extensive interests since the compound possesses the lowest density [4] and the best oxidation resistance [5] of the MAX family. However, as for other ceramics, the synthesis of bulk $\mathrm{Ti}_{2} \mathrm{AlC}$ ceramics has proven to be difficult $[6,7]$. Therefore, studies devoted to the joining of $\mathrm{Ti}_{2} \mathrm{AlC}$ ceramics are of great significance for applications [8].

Only a few efforts have been carried out to study the joining of $\mathrm{Ti}_{2} \mathrm{AlC}$ phases, among which the diffusion technique is the mostly adopted one. These studies revealed that the formation of $\mathrm{Ti}_{2} \mathrm{AlC}-\mathrm{MAX}$ diffusion couples requires high temperature, along with a long diffusion time [9]. Such conditions are often unfavorable for the thermal stability of the $\mathrm{Ti}_{2} \mathrm{AlC}$ ceramic substrates. In addition, mechanical tests of $\mathrm{Ti}_{2} \mathrm{AlC}$-metal diffusion couples [10] exhibit low mechanical strength in general, which is mainly attributed to the large mismatch of the coefficients of thermal expansion of the two materials. Among the various existing joining techniques, brazing is one of the most promising for joining MAX phases, especially concerning the ceramic-metal joints [11]. In the brazing of some traditional ceramic materials, the poor wettability of the molten metallic alloys on the ceramic surface is always a critical problem, which requires to be overcome. Usually, it is done by introducing some reactive elements in 
the brazing filler or by including a surface modification of the ceramic substrates. However, there is still no literature reporting on the fundamental wetting behaviors of the liquid brazing filler onto the $\mathrm{Ti}_{2} \mathrm{AlC}$ ceramics at this moment. The present work aims at illustrating the wetting behaviors of some fillers on the $\mathrm{Ti}_{2} \mathrm{AlC}$ substrate, thereby disclosing the wetting mechanisms of this MAX phase.

\section{Materials and methods}

Since the elimination of the $A$ element in a MAX compound is considered to be the major factor accounting for its decomposition behavior [12], two kinds of fillers are chosen in this work: Nickel based fillers (including BNi-2 alloy and NiPd eutectic alloy) which are reactive to the $A$ element, and aluminum based fillers (including the pure Al metal filler and AlSi eutectic alloy) which are not. All these fillers are provided in powder state with an average particle size of $50 \mu \mathrm{m}$, by Shanghai Simike Welding Materials Limited Company, China. The wetting experiments were carried out in a high vacuum furnace (VAF-30, working at around $10^{-3} \mathrm{~Pa}$ ). The contact angle during the experiment was recorded with the camera (DV-HV 1303UM) equipped on the furnace, and the cooling speed was $5{ }^{\circ} \mathrm{C} /$ minute after wetting experiments. Finally, the cross-section morphology was investigated using a scanning electron microscope (SEM, Sigma 500, Zeiss).

\section{Results and discussion}

Fig. 1 shows the variations of the contact angle $\theta$ as a function of temperature $T$. It suggests that the two kinds of fillers possess different wetting behaviors on the 
$\mathrm{Ti}_{2} \mathrm{AlC}$ ceramics. The contact angle of the two nickel based filler alloys, as displayed in Fig. 1(a), both stay lower than $90^{\circ}$ during the whole wetting process, and can even reach as small as $20^{\circ}$ finally. Although the presence of the additive $\mathrm{Cr}$ and $\mathrm{B}$ elements in the BNi-2 filler alloy is believed to be favorable for the wetting process, it is still reasonable to deduce that the nickel melts possess excellent wettability on the $\mathrm{Ti}_{2} \mathrm{AlC}$ ceramics. On the contrary, the two aluminum fillers, shown in Fig. 1(b), are not wettable on the ceramic surface, whose contact angle keeps larger than $135^{\circ}$. It is worthwhile pointing out that the presence of the Si element in the AlSi eutectic filler contributes to a smaller contact angle at the initial wetting stage, however, it does not alter the non-wetting behavior of the filler on the $\mathrm{Ti}_{2} \mathrm{AlC}$ ceramics. Therefore, it can be safely assumed that the aluminum melts possess poor wettability on the $\mathrm{Ti}_{2} \mathrm{AlC}$ ceramics.
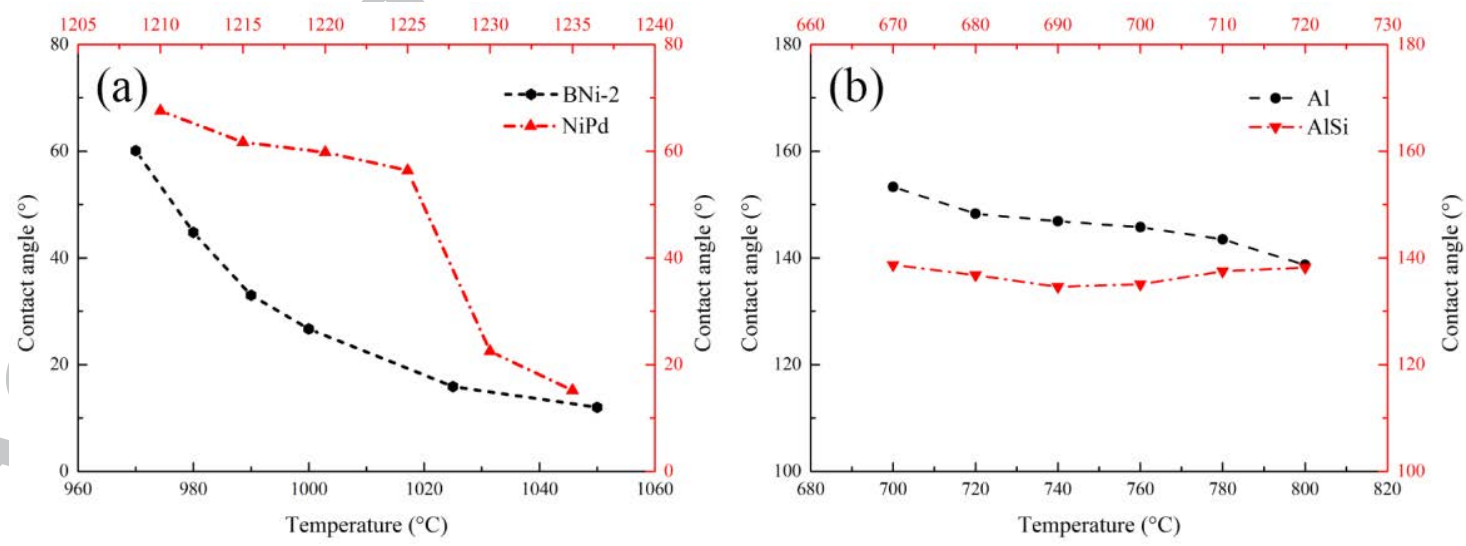

Fig. 1. Variations in the contact angle $\theta$ as a function of temperature $T$ for the $\mathrm{Ti}_{2} \mathrm{AlC}$ ceramics wetted by (a). Nickel based fillers; (b). Aluminum based fillers.

The cross-section of the $\mathrm{BNi}-2 / \mathrm{Ti}_{2} \mathrm{AlC}$ wetting sample is displayed in Fig. 2. In the left side of the figure the original separation surface is clearly apparent. 
Accordingly, the reaction layer can be divided into two regions: beneath the original surface, there exists a diffusion area, which is supposed to be a solid state reaction during the wetting experiments since a highly ordered microstructure can be observed; above the original interface, there exists the solidified filler melt with the typical isothermal solidification microstructure of $\mathrm{BNi}-2$ filler alloy [13], which is considered to be liquid state during the wetting experiments. Fig. 2(b) shows the magnified morphology of the cross-section area. Beneath the original surface, the formation of the interaction area is likely to be related to the diffusion behavior of the Ni element in the $\mathrm{Ti}_{2} \mathrm{AlC}$ substrate. In addition, some modified $\mathrm{Ti}_{2} \mathrm{AlC}$ (with lighter contrast in the figure when compared to the unmodified $\mathrm{Ti}_{2} \mathrm{AlC}$ substrate) can be observed, which is assumed to be the original grain boundary according to the distribution morphology. Therefore, it is suggested that the nickel element from the brazing filler diffuses into the $\mathrm{Ti}_{2} \mathrm{AlC}$ substrate mainly along the grain boundary, and then contributes to the formation of the interaction layer with the increasing nickel content. The average chemical composition of the interlayer is determined from EDS analysis to be 28.1 at.\%, 11.8 at. $\%, 31.7$ at. $\%$ and 28.4 at. $\%$ for $\mathrm{Ti}, \mathrm{Al}, \mathrm{C}$ and $\mathrm{Ni}$ elements, respectively. Thus it is assumed to be a mixture of $\mathrm{Ni}_{3}(\mathrm{Al}, \mathrm{Ti})$ and $\mathrm{TiC}_{\mathrm{x}}$. It can be concluded from the above analysis that the diffusion of $\mathrm{Ni}$ element from the filler in the $\mathrm{Ti}_{2} \mathrm{AlC}$ substrate accounts for the formation of a thick interaction layer. In addition, the presence of the additive elements (The $\mathrm{B}$ element for example) in the $\mathrm{BNi}-2$ filler contributes to a strong interaction between the melt and the substrate, thereby leading 
to a quick reduction in the contact angle. However, for the NiPd filler, without the assistance of the reactive elements, the formation of the interaction layer by diffusion of $\mathrm{Ni}$ and $\mathrm{Pd}$ elements in the $\mathrm{Ti}_{2} \mathrm{AlC}$ substrate requires some time, which accounts for the slow reduction rate in the contact angle at the initial stage. Afterwards, the following wetting process is promoted with the formation of interaction layer, then the contact angle decreases rapidly. In conclusion, the formation of the interaction layer is assumed to be the major wetting mechanism of the nickel fillers on the $\mathrm{Ti}_{2} \mathrm{AlC}$ ceramics.
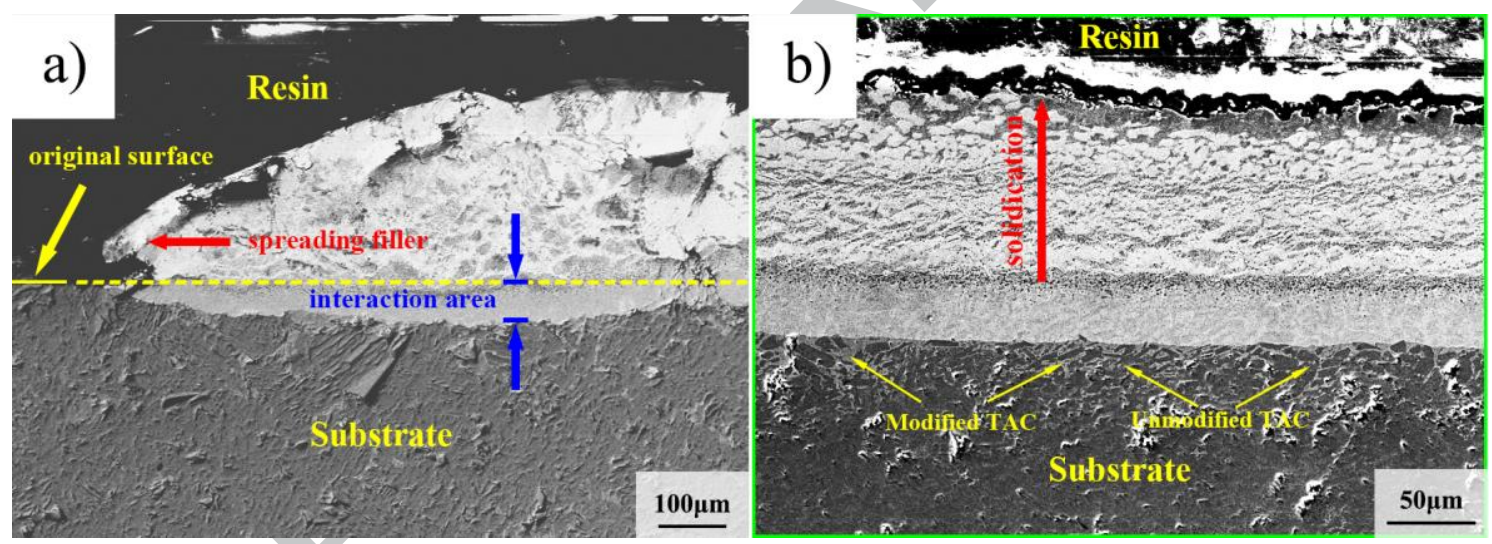

Fig. 2. Cross-section morphology of the $\mathrm{BNi}-2 / \mathrm{Ti}_{2} \mathrm{AlC}$ wetting sample: (a). morphology of the edge region; (b). morphology of the middle region.

The cross-section morphology of the $\mathrm{Al} / \mathrm{Ti}_{2} \mathrm{AlC}$ wetting sample is displayed in Fig. 3(a) and (b). No interaction area in the $\mathrm{Ti}_{2} \mathrm{AlC}$ substrate can be observed around the wetting surface: the flat morphology remains unchanged, and the chemical composition ratio of $\mathrm{Ti}$ : $\mathrm{Al}$ : $\mathrm{C}$ stays $2: 1: 1$ in the $\mathrm{Ti}_{2} \mathrm{AlC}$ grains nearby according to the EDS results. In order to reveal the functionalization mechanisms of the pure Al filler metal on the $\mathrm{Ti}_{2} \mathrm{AlC}$ ceramics, a supplementary wetting experiment has been carried 
out, using an $\mathrm{Al}$ foil with a thickness of $20 \mu \mathrm{m}$. Instead of gathering together to form a liquid sphere when the $\mathrm{Al}$ powders are heated, the molten $\mathrm{Al}$ foil spills on the surface, and then interacts with the $\mathrm{Ti}_{2} \mathrm{AlC}$ ceramics during the wetting process. It finally contributes to the formation of the surface with the morphology displayed in Fig. 3 (c) and (d). It can be observed from the Fig. 3(c) that a mass of grey phase with sheet morphology forms on the surface. It is identified as the intermetallic compound $\mathrm{TiAl}_{3}$ according to the EDS result. Fig. 3(d) shows the magnified morphology of the fine particles, and the corresponding chemical composition is found to be 4.9 at.\% and 85.1 at.\% for $\mathrm{Ti}$ and $\mathrm{Al}$ elements, respectively, suggesting to be a solidified $\mathrm{Al}$ melt on the $\mathrm{Ti}_{2} \mathrm{AlC}$ substrate. The formation of the $\mathrm{TiAl}_{3}$ compound is most probably considered to be due to the decomposition of the $\mathrm{Ti}_{2} \mathrm{AlC}$ ceramics thereby providing a source of $\mathrm{Ti}$ element. However, this reaction does not improve the wettability of the Al filler on the $\mathrm{Ti}_{2} \mathrm{AlC}$ ceramics, because the reaction product, the $\mathrm{TiAl}_{3}$ compound, comes into during the solidification period. It is worthwhile pointing out that the additive $\mathrm{Si}$ element is able to diffuse into the $\mathrm{Ti}_{2} \mathrm{AlC}$ substrate during the wetting experiment. The diffusion behavior is likely to be favorable for promoting the interaction between the melt and the $\mathrm{Ti}_{2} \mathrm{AlC}$ substrate, which accounts for the smaller contact angle at the initial wetting stage. However, the formation of the $\mathrm{Ti}_{2}(\mathrm{Al}, \mathrm{Si}) \mathrm{C}$ promotes little to the wetting behavior of the AlSi filler on the $\mathrm{Ti}_{2} \mathrm{AlC}$ ceramics, and fails to alter the non-wetting phenomenon of the Al melt on the ceramic surface, whose contact angle remains around $135^{\circ}$ during the whole wetting experiment. 

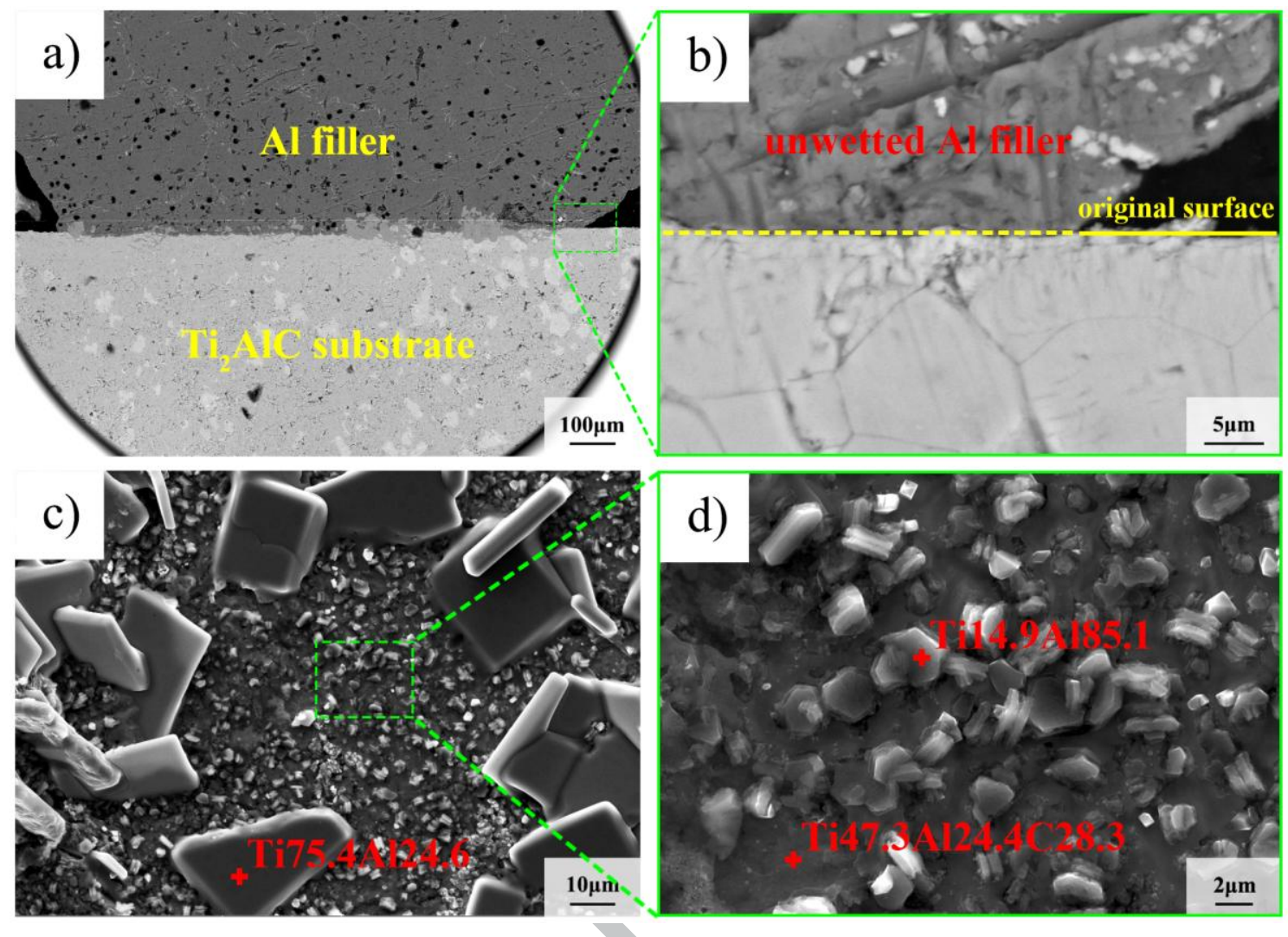

Fig. 3. Morphology of the $\mathrm{Al} / \mathrm{Ti}_{2} \mathrm{AlC}$ sample: (a). cross-section; (b). triple line; (c).

surface morphology of the reacted area; (d). magnified morphology of the particles.

\section{Conclusions}

In summary, the two kinds of brazing fillers examined in this present work possess different wettability on the $\mathrm{Ti}_{2} \mathrm{AlC}$ ceramics. The nickel based filler alloys are wettable, with the contact angle reaches as low as $20^{\circ}$ finally, which is mainly ascribed to the interaction between $\mathrm{Ni}$ filler and $\mathrm{Ti}_{2} \mathrm{AlC}$ substrate. On the contrary, the aluminum based filler alloys are non-wettable on the ceramic surface, whose contact angle remains higher than $135^{\circ}$ during the whole wetting experiments. The weak interaction between $\mathrm{Al}$ filler and $\mathrm{Ti}_{2} \mathrm{AlC}$ substrate should be blamed for the poor wettability. Therefore, the active $\mathrm{Al}$ atoms in the $\mathrm{Ti}_{2} \mathrm{AlC}$ structure are considered to be 
the major factor promoting the wetting process, as a result, neither the active brazing elements nor the surface pretreatment are required for the wetting and brazing of $\mathrm{Ti}_{2} \mathrm{AlC}$ ceramics in most cases, and those fillers which are reactive to the $\mathrm{Ti}_{2} \mathrm{AlC}$ substrate, for example, the nickel based fillers in this work, are more suitable for the brazing of $\mathrm{Ti}_{2} \mathrm{AlC}$ ceramics.

\section{Acknowledgements}

This work was financially supported by the National Natural Science Foundation of China (NSFC) under Grant Nos. 51372049, 51621091 and U1537206. The author gratefully acknowledges the funding from China Scholarship Council (CSC).

\section{References}

[1] M.W. Barsoum, D. Brodkin, T. El-Raghy, Scripta Mater. 36(5) (1997) 535-541.

[2] M. Radovic, M.W. Barsoum, Am. Ceram. Soc. Bull. 92(3) (2013) 20-27.

[3] M.W. Barsoum, Prog. Solid State Chem. 28(1-4) (2000) 201-281.

[4] Z.M. Sun, Int. Mater. Rev. 56(3) (2011) 143-166.

[5] J.L. Smialek, Oxid. Met. 83(3-4) (2015) 351-366.

[6] S.R. Kulkarni, A. Wu, J. Alloy. Compd. 490(1-2) (2010) 155-159.

[7] Y.L. Bai, H.X. Zhang, X.D. He, et al, Int. J. Refract. Met. Hard Mat. 45 (2014) $58-63$.

[8] R.E. Loehman, A.P. Tomsia, Am. Ceram. Soc. Bull. 67(2) (1988) 375-380.

[9] A. Ganguly, M.W. Barsoum, R.D. Doherty, J. Am. Ceram. Soc. 90(7) (2007) 2200-2204. 
[10] D.J. Tallman, J. Yang, L. Pan, et al, J. Nucl. Mater. 460 (2015) 122-129.

[11] N. Eustathopoulos, M.G. Nicholas, B. Drevet, Wettability at high temperatures, Elsevier1999.

[12] W.K. Pang, I.M. Low, B.H. O'Connor, et al, J. Alloy. Compd. 509(1) (2011) 172-176.

[13] S.K. Tung, L.C. Lim, M.O. Lai, Scripta Mater. 34(5) (1996) 763-769. 